\title{
What we have to know about corticosteroids use during Sars-Cov-2 infection
}

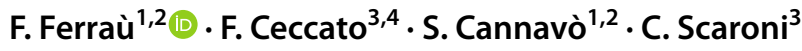

Received: 1 June 2020 / Accepted: 2 August 2020 / Published online: 28 August 2020

(C) Italian Society of Endocrinology (SIE) 2020

\begin{abstract}
Purpose Glucocorticoids (GCs), alone or associated to other drugs, were widely used in the management of patients affected by severe acute respiratory syndrome caused by SARS-CoV-2 infection, during the recent COVID-19 outbreak. This review summarizes the available data on HPA axis impairment in GC-treated SARS-CoV-2 patients, focusing on the risk of adrenal insufficiency and on potential drug interactions during concomitant treatments.

Methods Literature on the impact of GCs therapy on HPA axis and on the consequences of coadministration of GCs and other drugs in SARS-CoV-2 patients has been reviewed.

Results GC treatment can cause symptoms of hypercortisolism, especially in patients with individual hypersensibility, or hypoadrenalism after drug withdrawal, due to hypothalamic-pituitary-adrenal (HPA) axis suppression, with consequences in terms of increased morbidity and mortality risk. On the other hand, in SARS-CoV-2-infected patient's cortisol secretion could be insufficient also due to critical illness-related corticosteroid insufficiency (CIRCI). In addition, in this clinical context, the co-administration of antiretroviral drugs and corticosteroids may trigger drug-drug interaction and enhance the exposure to the latter ones, metabolized through the CYP450 CYP3A pathway, severely impacting on HPA axis.

Conclusion Physicians involved in the management of patients affected by COVID-19 should be aware of the need of an appropriate GC dose tapering, and of potential interaction of GCs with antiviral therapy and drugs used to treat associated co-morbidities.
\end{abstract}

Keywords Glucocorticoid treatment · COVID-19 - SARS-CoV 2 - Drug interference · Adrenal insufficiency · Steroids · Infection

FF and FC should be considered jointly as first co-authors.

F. Ferraù

francesco.ferrau1@gmail.com; fferrau@unime.it

1 Department of Human Pathology of Adulthood and Childhood 'G. Barresi', AOU Policlinico Gaetano Martino, UOC di Endocrinologia, University of Messina, Pad. H, $4^{\circ}$ piano, Via Consolare Valeria, 1, 98125 Messina, Italy

2 Endocrine Unit, University Hospital G. Martino, Messina, Italy

3 Endocrinology Unit, Department of Medicine DIMED, University-Hospital of Padova, Padova, Italy

4 Department of Neuroscience DNS, University of Padova, Padova, Italy

\section{Introduction: glucocorticoids use during critical illness}

During the Covid-19 outbreak occurring in Italy in the spring of 2020, glucocorticoids' (GCs) administration, alone or associated with other drugs, was widely used in the management of patients affected by severe acute respiratory distress syndrome (ARDS) caused by Sars-Cov-2 infection. Nevertheless, several concerns exist about this therapeutic approach in patients with viral infections.

Some studies demonstrated that GCs administration increases the occurrence of nosocomial infections and mortality in patients with seasonal/mixed seasonal or A/ H1N1 flu [1, 2]. In addition, data collected during previous pandemics, as severe acute respiratory syndrome (SARS) or middle east respiratory syndrome (MERS), are contradictory about GCs efficacy and lethality reduction [3]. These evidences, however, relate to extremely high 
doses (>150 mg/day methylprednisolone dose equivalent) of GCs, and are of low quality and with potential confounding factors [2]. Indeed, some studies were performed in patients affected by ARDS or septic shock, while others enrolled patients in severe conditions and/ or resistant to conventional treatment, contexts that could increase mortality independently by GCs administration. Therefore, in a real-life clinical setting, physicians tend to use corticosteroids in most critically ill patients. The GCs doses used for treatment of community-acquired pneumonia in intensive care unit (ICU) are routinely low (32-40 $\mathrm{mg} /$ day methylprednisolone equivalent), in the majority of randomized controlled trials reported in the Cochrane review [4]. At these doses, GCs not only inhibit immune responses and pathogen clearance, but also suppress lung inflammation.

On the other hand, prolonged steroids treatment can cause symptoms of hypercortisolism, especially in patients with individual hypersensibility, or hypoadrenalism after drug withdrawal, due to hypothalamic-pituitary-adrenal (HPA) axis suppression. Moreover, the co-administration of antiretroviral drugs may affect GC metabolism, as detailed below in the dedicated section.

A recent study, the RECOVERY trial published in July 2020 , reported that dexamethasone is effective in reducing intermediate (28-day) mortality among patients who were receiving either invasive mechanical ventilation or oxygen alone [5]. The dose considered were quite high (6 mg) for a brief period (up to 10 days), both oral or iv. Nonetheless, dexamethasone is the most potent synthetic GC and is as effective as anti-inflammatory as potent to suppress hypothalamic-pituitary CRH-ACTH feedback [6]. Therefore, further studies to consider pros and cons of dexamethasone use in clinical practice are suggested.

In patients affected by Covid-19 and treated with high doses of intermediate/long acting steroids (summarized in Table 1), it is necessary to perform an appropriate dose tapering, but guidelines or consensus statements are unfortunately lacking. All these patients, as well as those assuming chronically GCs for treatment of primary or central hypoadrenalism, have to titrate the GCs dose if fever, cough or gastrointestinal symptoms (vomiting and diarrhoea) occur and to undergo urgent medical evaluation. To conclude, the prevalence of adrenal insufficiency (AI) following corticosteroid administration is unknown; this condition is frequently underdiagnosed, especially when patients are evaluated by non-endocrinologists.

This review summarizes the available data on HPA axis impairment in GC-treated Sars-Cov2 patients, focusing on the risk of adrenal insufficiency and on potential drug interactions during concomitant treatments.
Table 1 Corticosteroid Equivalency Table

\begin{tabular}{lll}
\hline & $\begin{array}{l}\text { Glucocorticoid } \\
\text { equivalent }\end{array}$ & $\begin{array}{l}\text { Mineral- } \\
\text { corticoid } \\
\text { equivalent }\end{array}$ \\
\hline Cortisol & 1 & 1 \\
Hydrocortisone & 1 & 1 \\
Cortisone acetate & 0.8 & 0 \\
Prednisolone & 4 & 0.8 \\
Deflazacort & 4 & 1 \\
Methylprednisolone & 5 & 0.5 \\
Triamcinolone & 5 & 0 \\
Fludrocortisone & 12 & 125 \\
Betamethasone & 25 & 0 \\
Dexamethasone & 26 & 0 \\
\hline
\end{tabular}

\section{Risk of adrenal insufficiency in patients with Covid-19}

In patients with SARS-CoV-2 infections, Covid-19 disease with its consequences, individual conditions and GCs treatment can induce primary or secondary AI, which could be even combined.

In the course of COVID-19 outbreak, GCs have been extensively introduced in the management of patients affected by Sars-Cov-2. Steroid administration in this contest is justified by increasing evidences suggesting that an abnormal immune reactivity, maybe more than uncontrolled viral replication, could be responsible for lung damage and progression to severe respiratory failure, causing in turn disease-dependent lethality [7]. A similar mechanism was recognized in SARS [8]. On the other hand, endogenous cortisol exerts a crucial role in inflammation control, through its anti-inflammatory and vascular-protective properties, and activation of HPA axis occurs in patients with critical illnesses, as sepsis or severe pneumonia. Indeed, some studies showed that antibodies against Sars-Cov-2 could destroy circulating ACTH and in turn blunt the stress-induced cortisol rise for several months [9]. Based on these evidences, GCs' treatment was also introduced in the management of some virus-induced pneumonia. Nevertheless, exogenous steroids administration disrupts circadian cortisol rhythm and per se exposes patients to the risk of post-treatment hypoadrenalism [10]. Indeed, driven by nocturnal ACTH increase, endogenous cortisol concentration peaks in the morning, then slowly decreases during the day and drops down to the lowest levels in the late evening [11]. Therefore, high doses of GCs, especially long-acting formulations or given during the evening-night (usual in an ICU or other critical care area or emergency department), suppress ACTH secretion, thus 
resulting in a prolonged suppression of HPA axis [12]. It is noteworthy that circadian cortisol oscillation is crucial for biological function and that it is a major synchronizer of the circadian system that involves also peripheral clocks in many tissues, i.e., adrenal glands. The misalignment between central and peripheral clocks has a host of physical and psychological adverse effects. As consequence, also the timing of GCs' administration differently affects the degree of HPA axis suppression.

AI is defined by the inability of the adrenal cortex to produce a sufficient amounts of GCs and/or mineralocorticoids $[13,14]$, a condition that may increase morbidity and mortality risk [15]. Patients with hypoadrenalism complain of symptoms as fatigue, hypotension, loss of weight, nausea, vomiting, abdominal pain [15]; moreover, some symptoms of AI, as hyponatremia, can characterize COVID-19 also in adrenal-sufficient patients [16]. Secondary AI is caused by diseases or injury involving hypothalamus or pituitary gland [14], or by prolonged use of corticosteroids, as previously mentioned. The same effect can be induced by other chemicals that suppress CRH and/or ACTH secretion [10]. Central $\mathrm{AI}$ is characterized by inappropriate ACTH secretion, with consequent impairment of cortisol synthesis and secretion. In central AI the renin-aldosterone system is preserved, as opposite to primary AI, and hyperkalaemia or pigmentation is not clinical features of ACTH deficiency [17].

Coronavirus is able to variously affect HPA axis. A direct negative effect on pituitary corticotroph cells was described during previous SARS outbreak in 2002-2003: according to both basal serum cortisol and dynamic test (especially the low-dose short synacthen test), up to $40 \%$ of the cohort was found with an insufficient HPA axis [18]. Recently, a primary adrenal injury consistent with bilateral adrenal haemorrhage has been reported in a patient with Covid-19 infection [19].

High doses and/or prolonged administration of GCs increases AI risk [5], but also the recovery of HPA function displays a considerable individual variability. This could be due to individual differences in pro-inflammatory cytokine secretion that inhibit HPA axis, together with different substrate availability for steroid synthesis, vascular damage of adrenal glands and peripheral corticosteroid resistance. Hypothalamus, pituitary and adrenal cells are strictly controlled by several hormones, peptides, cytokines and other factors, in basal condition and during critical illness [20]. For instance, ACTH- independent inflammation-driven activation of Toll- like receptor two and four in adrenocortical cells directly activates cortisol production [21]. Moreover, during critical illness, there is an increase of free cortisol levels, secondary not only to increased secretion, but also to reduced plasma binding activity, to reduced glucocorticoid receptor activity and to decreased cortisol clearance by the $11 \beta$ - hydroxysteroid dehydrogenase type 2 [20]. Moreover, impaired cytokine balance (higher levels of IL-6, IL-10 and TNF- $\alpha$ ) is observed in patients with Critical-illness Related Corticosteroid Insufficiency (CIRCI) [22]. Indeed, CIRCI does not indicate strictly a pituitary or adrenal injury, but rather a condition of relative $\mathrm{AI}$ resulting from inadequate glucocorticoid-mediated anti-inflammatory activity in relation to the severity of stress caused by a critical illness [23]. In CIRCI there is not an organic defect of HPA axis; however, the systemic availability of cortisol is assumed to be insufficiently high to face the stress of the illness [20, 24]. In this condition, either CRH and ACTH synthesis or adrenal steroidogenesis is impaired [24]. CIRCI occurs in some ICU-admitted patients: in selected cases, GC treatment is currently recommended [20, 25]. To conclude, in patients with critical illness (acute distress syndrome, pneumonia, shock) combined with Sars-Cov-2 infection, cortisol secretion could be insufficient, as a result of primary and secondary AI combination.

AI following GC discontinuation is relatively frequent, despite it is sometimes unrecognized, but there are not GC administration regimen, titration, treatment duration, or underlying health problems that could predict or exclude its occurrence. Some studies reported that higher the GC doses and/or more prolonged the time of administration, higher the AI risk [12, 26]. A meta-analyses published in 2015 reported that the risk of secondary $\mathrm{AI}$ is dependent on the administration route, being higher if GCs are administered orally or by intra-articular injection (respectively, $48.7 \%$ and $52.2 \%$ of cases), and lower by inhalation, or if administered topically or by intranasal spray $(7.8 \%, 4.7 \%$ and $4.2 \%$, respectively) [26]. Use of low, medium, or high GC doses results in an $\mathrm{AI}$ prevalence of $2.4 \%, 8.5 \%$ and $21.5 \%$, respectively. A short, medium, or long-duration treatment $(<1$ month, 1 month-1 year, $>1$ year, respectively) resulted in an AI rate of $1.4 \%, 11.9 \%$ and $27.4 \%$ [26]. In a recent study, AI was observed in patients taking prednisolone $5 \mathrm{mg}$ per day, with a mortality increase following treatment interruption [27]. Nonetheless, the risk of AI post COVID-19 infection in patients treated with high-dose GCs (as those with Graves' orbitopathy [28]) is not yet reported. Nonetheless, the pulse immunosuppressive GC treatment for ophthalmopathy does not increase the risk of secondary AI [29, 30].

Therefore, in patients with active or recently resolved Covid-19 infection, AI can be the result of HPA axis impairment due to infection (a case of CIRCI), combined with the consequence of GC withdrawal [31]. It is important to consider that there are no prospective studies on the best way to withdraw this therapy; therefore, most clinicians skilled in the use of GCs have developed their own tapering regimens that are suitable in real-life clinical experience [32], both to avoid AI and to increase patient's adherence and compliance. According with an experience-based approach, methylprednisolone was administered in most severe COVID-19 
patients, at the dose of $1 \mathrm{mg} / \mathrm{kg} / \mathrm{day}$, or dexamethasone during the post-acute phase of the disease, at the dose of $2 \mathrm{mg} /$ day for a long time.

Beside the use of GCs therapy in patients with Covid-19 infections, some previous conditions may partially impair the HPA axis, thus increasing the risk of AI after GC withdrawal. In fact central AI is common after pituitary or cranial radiation for intracerebral/nasopharyngeal tumours and total body irradiation for haematological malignancies (ranging from 12 to $68 \%$ [33-35], with similar risk with fractionated, proton beam or stereotactic radiotherapy). It can take a few years to develop, with incidence of all pituitary hormone deficiencies, almost doubling between years 2 and 7 of follow-up [36, 37]. Moreover, also traumatic brain injury or subarachnoid haemorrhage [13], infectious meningitis or pituitary abscess $[38,39]$ are conditions at high-risk for central AI. Moreover, all patients with known adrenal insufficiency must follow the "sick-day rules", increasing their usual substitutive GC treatment [40]. All these situations are not so rare in the general population and have to be recognized also in patients admitted for Sars-Cov-2 infection and subjected to steroid therapy.

\section{GC and drug interference}

Side effects on HPA axis function are also common in patients treated with other medications that can alter the pharmacodynamics of GCs, potentiating their effects. CYP3A4 is the dominant isoenzyme of the hepatic cytochrome $\mathrm{P} 450$ system and is the primary metabolic step for the degradation of endogenous and most prescribed GCs. The concomitant use of drugs modulating cytochrome $\mathrm{P} 450$ 3A4 activity can increase the bioavailability of synthetic steroids leading to iatrogenic Cushing syndrome (ICS) and influencing the degree of inhibition of the HPA axis. On the other hand, GCs can themselves influence and regulate many xenobiotic-metabolizing enzymes of the cytochrome P450 superfamily, via several molecular mechanisms, underpinning potentially dangerous interactions with concomitantly administered drugs, with serious clinical consequence [41, 42].
GCs, having anti-inflammatory, immunosuppressive and antiproliferative properties are commonly used in clinical practice in the treatment of several inflammatory and autoimmune disorders. They are generally administered in complex therapeutic regimens, which might amplify the risk of drug-drug interactions, especially in the elderly [42].

GCs exert an anti-inflammatory action by inhibiting pro-inflammatory genes which encode for cytokines, chemokines, cell adhesion molecules, inflammatory enzymes and receptors involved in the inflammatory process. Therefore, GCs are often used as treatment/co-treatment in several infectious diseases including viral pneumonia. World is nowadays facing the global pandemic of the coronavirus SARS-CoV-2 infection causing COVID-19 disease. There is yet no specific treatment for COVID-19 patients, who can be administered antibiotics, antivirals, and in some cases GCs, with oxygen therapy and non-invasive ventilation for the most severely affected patients. Several randomized controlled trials are underway testing antiviral medications targeting different components of the SARS-CoV-2 lifecycle, including the following: (i) the viral entry into the host cells, by using chloroquine/hydroxychloroquine, umifenovir and interferon; (ii) the viral RNA synthesis, by administering remdesivir, favipiravir and ribavirin; (iii) and the viral replication, by using lopinavir-ritonavir and darunavir-cobicistat combination. On the other hand, in this setting, the therapeutic role of GCs remain controversial, as WHO suggest their use only to be considered if required for an alternative indication (i.e., septic shock, bronchoconstriction) [43].

In this clinical context, the potential risk of significant pharmacokinetic drug interactions between antiretroviral therapy and GCs treatment cannot be underestimated (Table 2). Several reports, mainly based on therapeutic experience in HIV-infected patients, have documented both iatrogenic severe AI and ICS in patients concomitantly receiving GCs and a ritonavir boosted antiretroviral regimen [44, 45]. These complications result from ritonavir-mediated inhibition of CYP3A4 enzymes, which increases the levels of GCs that are also metabolized via the same enzymatic system. Most cases of ritonavir-associated adrenal suppression have involved inhaled fluticasone [46-52]. AI secondary to

Table 2 Potential consequences of co-administration of glucocorticoids (GCs) and therapeutic agents used against Sars-COV-2 infection (TAS) and effects on HPA axis

\begin{tabular}{lll}
\hline TAS & GCs-TAS interaction & Effects on HPA axis \\
\hline $\begin{array}{l}\text { Ritonavir, Lopina- } \\
\text { vir, Cobicistat }\end{array}$ & $\begin{array}{c}\text { GCs increased bioavailability (fluticasone, budesonide, mometasone, triamci- } \\
\text { nolone, prednisone, prednisolone/ methylprednisolone, dexamethasone) }\end{array}$ & Potential impairment of HPA axis (ICS/AI) \\
$\begin{array}{l}\text { Darunavir } \\
\text { Hydroxicloroquine }\end{array}$ & GCs interference on darunavir plasma concentration^ & - \\
Interferon alfa/beta & $\begin{array}{c}\text { Potential effects on GCs bioavailability via modulation CYP3A expression/ } \\
\text { activity (in vitro) } ?^{\wedge}\end{array}$ & - \\
& Functional alteration of HPA axis^ \\
\hline
\end{tabular}

^very limited data; ICS iatrogenic Cushing's syndrome; $A I$ adrenal insufficiency 
inhaled steroid drugs is uncommon, but its frequency can increase if the patient is also under treatment with inhibitors of cytochrome $\mathrm{P} 4503 \mathrm{~A} 4$, such as protease inhibitors or triazoles. Fluticasone has a higher lipophilicity and longer elimination half-life and, therefore, has a greater inhibitory effect on the HPA axis. In a pharmacovigilance retrospective study conducted in France, the prevalence of AI over a 5 -year period in patients treated with inhaled steroid drugs has been assessed. Forty-six cases were reported, 52\% of them with fluticasone, with drug interactions suspected in 12 cases: six for concomitant use of fluticasone and ritonavir [53].

Pharmacogenetic analysis, in particular CYP3A genotyping, provides useful information in patients treated for viral infections such as HIV, with respect to potential steroid co-treatment. In this regard, Van der Berg et al. reported a case of ICS consequent to fluticasone furoate in a paediatric patient treated for congenital HIV with a combination therapy of lopinavir/ritonavir. Pharmacogenetic analysis revealed that the patient carried the CYP3A $4 * 1 \mathrm{~B} / * 1 \mathrm{G}$ and CYP3A $5 * 3 / * 3$ genotype, which is associated with a partial and complete loss of enzyme activity, respectively [54]. Although most reported cases of Cushing's syndrome and AI due to associated treatment with ritonavir and exogenous GCs have been caused by inhaled fluticasone, treatment with other inhaled steroids, such as budesonide or mometasone, can also be troublesome [55-57]. Some reports have also described ICS/AI with GCs delivered through topical and injectable ocular preparations, as well as following intrabursal, intraarticular and epidural injections [58-60]. One report documented a case of ICS and secondary AI due to an interaction between ritonavir and GCs eye drops, while another described ICS following administration of orbital floor triamcinolone in a patient taking ritonavir-boosted lopinavir [61]. ICS has been also reported after co-administration of injected triamcinolone and ritonavir [62-64]. In a systematic review, 24 cases of injected triamcinolone-induced ICS have been reported: 11/24 cases were related to epidural injection, 7/24 to intra-articular, 3/24 to intramuscular and 3/24 to other injection sites. HPA axis suppression lasted beyond clinical recovery, for a median of 23 weeks after triamcinolone injection. In a multivariate Cox model, time to HPA axis recovery was shortened when ritonavir was withheld and was prolonged for higher dose of injected-triamcinolone or of ritonavir [65].

The time-span between initiation of ritonavir with GCs and the onset of symptoms of Cushing's syndrome or AI is highly variable, depending on the potency, dose and scheme of GC therapy. It is worth noting that while most of the literature has focused on complications from ritonavir combined with GCs, cobicistat (which is included in certain combination medications/schemes) is also a non-selective CYP3A4 inhibitor and could lead to the same complications if used with GCs [44]. In a retrospective case-control study describing ICS related to antiviral booster treatment, recorded in the French pharmacovigilance database between 1996 and 2018, among the 139 cases of ICS identified, 34 out of 35 cases of HIV-infected patients experienced drug-drug interaction (31 with ritonavir and three with cobicistat), as well as 7 out of 104 controls (uninfected people). The main corticosteroid involved was inhaled fluticasone among the patients and oral prednisone among the controls [66]. Indeed, caution should be exercised when oral or injectable forms of methylprednisolone or prednisolone are administered in patients taking antiretroviral regimens containing protease inhibitors or boosting agents such as ritonavir or cobicistat. One pharmacokinetic study revealed a $28 \%$ increase in prednisolone exposure when ritonavir was co-administered with its oral formulation [67]. Prednisolone is also known to have an incremented area under the plasma concentration versus time curve, with consequent increased effects, decreased oral clearance, with boosted absorption, when combined with ritonavir [68, 69]. As a consequence of GCs effects on the CYP3A4 enzymatic system, dexamethasone may also decrease levels of non-nucleoside reverse transcriptase inhibitors, compromising virologic efficacy [70].

Conversely, GCs can exert different effects on darunavir plasma concentrations, as showed in a study in which dramatic reduction in the plasma of darunavir concentrations occurred in one case while the other patient did not experience any difference in darunavir exposure during GCs therapy, as compared to pre-steroid co-administration. As mentioned before, genetic variants can contribute to intra- and inter-individual variability in CYP3A expression and activity; thus some authors suggested that the genetic background might potentially play a role in explaining the observed different effect of steroids on darunavir concentrations, as well as GC type and dose, and/or darunavir boosting agents (cobicistat versus ritonavir) [71].

On the other hand, treatment strategies of Sars-Cov-2 infection can take advantage of the use of other drugs, alone or in combination with other therapeutic agents, with different mechanisms of action, including chloroquine/hydroxychloroquine and interferons (mostly interferon $\alpha$ ).

In this regard, some reports identified CYP3As and CYP2D6 as the two major isoforms involved in the metabolism of chloroquine. In a study in patients with systemic lupus erythematous, low blood hydroxychloroquine concentration was associated with the absence of treatment with GCs, as if steroids may potentiate hydroxychloroquine, similar to their potentiation of oral anticoagulants, but -as stated by the Authors-this is completely hypothetical [72].

Interferon $\alpha(\mathrm{IFN}-\alpha)$ is used to treat chronic viral infections and has been found to decrease the rate of drug metabolism by acting on cytochrome P450 enzymes. Flaman et al. showed that IFN- $\alpha$ suppresses CYP3A4 expression in human 
hepatoma cells, suggesting caution when it is administered in combination with CYP3A4 substrates to avoid the occurrence of adverse drug interactions [73]. In another study, interferon was able to directly alter the expression of constitutive and inducible CYP3A genes in well-differentiated male rat hepatocytes in culture [74]. On the other hand, IFN- $\alpha$ /ribavirin administration was shown to affect adrenal function being associated with significant flattening of the diurnal ACTH and cortisol slope and increased evening plasma ACTH and cortisol concentrations [75]. Nonetheless, Interferon- $\beta$ (IFN- $\beta$ ) has been shown to modulate the induction of cytochrome P450 enzyme in mice [76]. Furthermore, IFN- $\beta$ has been found to affect neuroendocrine system in healthy subjects and multiple sclerosis patients as well, inducing an elevation of cortisol levels after acute injection [77, 78], while HPA hyperactivation would reduce with prolonged treatment.

In a COVID-19 ward there are involved several physicians, not only endocrinologists [79],; therefore, every clinician should be aware of potential interaction of GCs with antiretroviral therapy and drugs used to treat associated comorbidities. When ICS/AI is suspected, prompt evaluation and appropriate change and/or discontinuation of involved medications can prevent potentially fatal complications.

\section{Conclusions and future perspectives}

In the middle of Spring 2020, COVID-19 has affected millions people and caused hundreds of thousands of death overall. Although the disease is asymptomatic or paucisymtomatic in most cases, it can sometimes induce viral pneumonia, complicated by ARDS and/or sepsis. In addition, myocarditis and acute kidney injury were also diagnosed in some patients [80]. A specific and effective treatment was not found until now, but several experience-based approaches are proposed and some clinical trials are currently ongoing. Nevertheless, data about their effectiveness and safety are still lacking.

Despite several concerns about GC administration in patients with viral infections, they were extensively introduced in the management of most severely COVID-19-affected patients. Beside the anti-inflammatory, immunosuppressive and antiproliferative properties, their use could be justified in many cases for replacing CIRCI, a condition of relative functional AI frequently observed in patients with critical illnesses. On the other hand, GCs can induce ICS signs and symptoms or HPA axis impairment, with a variable risk related to the route, dose and length of administration, individual hypersensibility and interaction with other drugs. Indeed, antiviral or other drugs act as potent inhibitors of the cytochrome P4503A enzymes, enhancing the exposure to GCs, metabolized through the CYP450 CYP3A pathway, and prolonging their half-life. This effect can increase their bioactivity and induce longer-lasting suppression of HPA axis. Symptoms of hypoadrenalism are not specific and may be confused with those caused by a severe infectious disease. Moreover, especially in frail patients, steroids' withdrawal can also precipitate an adrenal crisis that represents a life-threatening complication. Unfortunately, there are no GCs administration regimen, titration, treatment duration, or underlying health problems that could predict or exclude its occurrence. For this reason, physicians involved in the management of patients affected by COVID-19 should be aware of performing an appropriate GCs dose tapering, even if guidelines or consensus statements are lacking.

On the other hand, GCs can themselves influence and regulate many xenobiotic-metabolizing enzymes of the cytochrome P450 superfamily, via several molecular mechanisms, underpinning potentially dangerous interactions with concomitantly administered drugs, with serious clinical consequence [25, 26]. For instance, some studies showed that GCs decrease plasma concentrations of antiviral drugs, e.g., ritonavir, at least in some cases. As mentioned before, genetic variants can contribute to intra- and inter-individual variability in CYP3A expression and activity, as well as GC type and dose.

In conclusion, present suggestions are based on prior experiences with SARS and on recent literature derived from small-scale studies, but analyses of data recorded during COVID-19 outbreak will increase our knowledge about GCs' effectiveness and safety and their antiviral drug interaction. There is an ample scope for future research on the field of these drugs, and we hope that this experience can teach us to better manage several endocrine and infectious diseases.

Funding This study did not receive any specific grant from any funding agency in the public, commercial or not-for-profit sector.

\section{Compliance with ethical standards}

Conflict of interest All authors declare that they have no conflicts of interest that might be perceived as influencing the impartiality of the reported research.

Research involving human participants Not applicable.

Informed consent Informed consent is not necessary in a reviewpublication.

\section{References}

1. Rodrigo C, Leonardi-Bee J, Nguyen-Van-Tam J, Lim WS (2013) Corticosteroids as adjunctive therapy in the treatment of influenza. In: Lim WS (ed) Cochrane Database of Systematic Reviews 
Chichester. John Wiley and Sons, UK, pp 98-106. https://doi. org/10.1002/14651858.CD010406

2. Lansbury LE, Rodrigo C, Leonardi-Bee J, Nguyen-Van-Tam J, Shen LW (2020) Corticosteroids as adjunctive therapy in the treatment of influenza: an updated cochrane systematic review and meta-analysis. Crit Care Med 48(2):e98-e106. https://doi. org/10.1097/CCM.0000000000004093

3. Lee N, Allen Chan KC, Hui DS et al (2004) Effects of early corticosteroid treatment on plasma SARS-associated Coronavirus RNA concentrations in adult patients. J Clin Virol 31(4):304-309. https://doi.org/10.1016/j.jcv.2004.07.006

4. Stern A, Skalsky K, Avni T, Carrara E, Leibovici L, Paul M (2017) Corticosteroids for pneumonia. Cochrane database Syst Rev 12:CD007720. https://doi.org/10.1002/14651858.CD007720. pub3

5. RECOVERY Collaborative Group (2020) Dexamethasone in hospitalized patients with Covid-19 - preliminary report. N Engl J Med 2:021436. https://doi.org/10.1056/NEJMoa2021436

6. Ceccato F, Artusi C, Barbot M et al (2020) Dexamethasone measurement during low-dose suppression test for suspected hypercortisolism: threshold development with and validation. J Endocrinol Invest. https://doi.org/10.1007/s40618-020-01197-6

7. Isidori AM, Pofi R, Hasenmajer V, Lenzi A, Pivonello R (2020) Use of glucocorticoids in patients with adrenal insufficiency and COVID-19 infection. Lancet Diabetes Endocrinol 8(6):472-473. https://doi.org/10.1016/S2213-8587(20)30149-2

8. Peiris JSM, Chu CM, Cheng VCC et al (2003) Clinical progression and viral load in a community outbreak of coronavirus-associated SARS pneumonia: a prospective study. Lancet 361(9371):17671772. https://doi.org/10.1016/S0140-6736(03)13412-5

9. Pal R, Banerjee M (2020) COVID-19 and the endocrine system: exploring the unexplored. J Endocrinol Invest 3:9

10. Grossman AB (2010) The diagnosis and management of central hypoadrenalism. J Clin Endocrinol Metab 95(11):4855-4863. https://doi.org/10.1210/jc.2010-0982

11. Ceccato F, Barbot M, Albiger N et al (2017) Daily salivary cortisol and cortisone rhythm in patients with adrenal incidentaloma. Endocrine. https://doi.org/10.1007/s12020-017-1421-3

12. Dinsen S, Baslund B, Klose M et al (2013) Why glucocorticoid withdrawal may sometimes be as dangerous as the treatment itself. Eur J Intern Med 24(8):714-720. https://doi.org/10.1016/j. ejim.2013.05.014

13. Bornstein SR, Allolio B, Arlt W et al (2016) Diagnosis and treatment of primary adrenal insufficiency: an endocrine society clinical practice guideline. J Clin Endocrinol Metab 101(2):364-389. https://doi.org/10.1210/jc.2015-1710

14. Isidori AM, Arnaldi G, Boscaro M et al (2020) Towards the tailoring of glucocorticoid replacement in adrenal insufficiency: the Italian society of endocrinology expert opinion. J Endocrinol Invest 43(5):683-696. https://doi.org/10.1007/s40618-019-01146 -y

15. Husebye ES, Allolio B, Arlt W (2014) Consensus statement on the diagnosis, treatment and follow-up of patients with primary adrenal insufficiency. J Intern Med 4:1. https://doi.org/10.1111/ joim. 12162

16. Berni A, Malandrino D, Parenti G, Maggi M, Poggesi L, Peri A (2020) Hyponatremia, IL-6, and SARS-CoV-2 (COVID-19) infection: may all fit together? J Endocrinol Invest. https://doi. org/10.1007/s40618-020-01301-w

17. Ceccato F, Scaroni C (2019) Central adrenal insufficiency: open issues regarding diagnosis and glucocorticoid treatment. Clin Chem Lab Med 57(8):1125-1135. https://doi.org/10.1515/ cclm-2018-0824

18. Leow MK-S, Kwek DS-K, NgAW-K O-C, Kaw GJ-L, Lee LS-U (2015) Hypocortisolism in survivors of severe acute respiratory syndrome (SARS). Clin Endocrinol (Oxf) 63(2):197-202. https ://doi.org/10.1111/j.1365-2265.2005.02325.x

19. Álvarez-Troncoso J, Zapatero Larrauri M, Montero Vega MD et al (2020) Case report: COVID-19 with bilateral adrenal hemorrhage. Am J Trop Med Hyg. https://doi.org/10.4269/ajtmh.20-0722

20. Téblick A, Peeters B, Langouche L, Van den Berghe G (2019) Adrenal function and dysfunction in critically ill patients. Nat Rev Endocrinol 15(7):417-427. https://doi.org/10.1038/s4157 4-019-0185-7

21. Bornstein SR, Ziegler CG, Krug AW et al (2006) The role of tolllike receptors in the immune-adrenal crosstalk. Ann N Y Acad Sci 1088(1):307-318. https://doi.org/10.1196/annals.1366.027

22. Kwon YS, Suh GY, Jeon K et al (2010) Serum cytokines and critical illness-related corticosteroid insufficiency. Intensive Care Med 36(11):1845-1851. https://doi.org/10.1007/s00134-010-1971-9

23. Annane D, Pastores SM, Rochwerg B et al (2017) Guidelines for the diagnosis and management of critical illness-related corticosteroid insufficiency (CIRCI) in critically ill patients (Part I): society of critical care medicine (SCCM) and European Society of Intensive Care Medicine (ESICM) 2017. Intensive Care Med 43(12):1751-1763. https://doi.org/10.1007/s00134-017-4919-5

24. Reddy P (2011) Clinical approach to adrenal insufficiency in hospitalised patients. Int J Clin Pract 65(10):1059-1066. https://doi. org/10.1111/j.1742-1241.2011.02718.x

25. Pastores SM, Annane D, Rochwerg B (2018) Guidelines for the diagnosis and management of critical illness-related corticosteroid insufficiency (CIRCI) in critically ill patients (Part II): Society of Critical Care Medicine (SCCM) and European Society of Intensive Care Medicine (ESICM) 2017. Intensive Care Med 44(4):474-477. https://doi.org/10.1007/s00134-017-4951-5

26. Broersen LHA, Pereira AM, Jørgensen JOL, Dekkers OM (2015) Adrenal insufficiency in corticosteroids use: systematic review and meta-analysis. J Clin Endocrinol Metab 100(6):2171-2180. https://doi.org/10.1210/jc.2015-1218

27. Mebrahtu TF, Morgan AW, Keeley A, Baxter PD, Stewart PM, Pujades-Rodriguez M (2019) Dose dependency of iatrogenic glucocorticoid excess and adrenal insufficiency and mortality: a cohort study in England. J Clin Endocrinol Metab. https://doi. org/10.1210/jc.2019-00153

28. Bartalena L, Chiovato L, Marcocci C, Vitti P, Piantanida E, Tanda ML (2020) Management of Graves' hyperthyroidism and orbitopathy in time of COVID-19 pandemic. J Endocrinol Invest. https ://doi.org/10.1007/s40618-020-01293-7

29. Jespersen S, Nygaard B, Kristensen LØ (2015) Methylprednisolone pulse treatment of Graves' ophthalmopathy is not associated with secondary adrenocortical insufficiency. Eur Thyroid J 4(4):222-225. https://doi.org/10.1159/000440834

30. Giotaki Z, Fountas A, Tsirouki T, Bargiota A, Tigas S, Tsatsoulis A (2015) Adrenal reserve following treatment of Graves' orbitopathy with intravenous glucocorticoids. Thyroid 25(4):462-463. https://doi.org/10.1089/thy.2014.0533

31. Scaroni C, Armigliato M, Cannavò S (2020) COVID-19 outbreak and steroids administration: are patients treated for SarsCov-2 at risk of adrenal insufficiency? J Endocrinol Invest 2(0123456789):3-4. https://doi.org/10.1007/s40618-020-01253-1

32. Iliopoulou A, Abbas A, Murray R (2013) How to manage withdrawal of glucocorticoid therapy. Prescriber 24(10):23-29. https ://doi.org/10.1002/psb.1060

33. Darzy KH (2013) Radiation-induced hypopituitarism. Curr Opin Endocrinol Diabetes Obes 20(4):342-353. https://doi. org/10.1097/MED.0b013e3283631820

34. Minniti G, Traish D, Ashley S, Gonsalves A, Brada M (2006) Fractionated stereotactic conformal radiotherapy for secreting and nonsecreting pituitary adenomas. Clin Endocrinol (Oxf) 64(5):542-548. https://doi.org/10.1111/j.1365-2265.2006.02506.x 
35. Li X, Li Y, Cao Y et al (2017) Safety and efficacy of fractionated stereotactic radiotherapy and stereotactic radiosurgery for treatment of pituitary adenomas: a systematic review and metaanalysis. J Neurol Sci 372:110-116. https://doi.org/10.1016/j. jns.2016.11.024

36. Appelman-Dijkstra NM, Kokshoorn NE, Dekkers OM et al (2011) Pituitary dysfunction in adult patients after cranial radiotherapy: systematic review and meta-analysis. J Clin Endocrinol Metab 96(8):2330-2340. https://doi.org/10.1210/jc.2011-0306

37. Kyriakakis N, Lynch J, Orme SM et al (2016) Pituitary dysfunction following cranial radiotherapy for adult-onset nonpituitary brain tumours. Clin Endocrinol (Oxf) 84(3):372-379. https://doi. org/10.1111/cen.12969

38. Tsiakalos A, Xynos ID, Sipsas NV, Kaltsas G (2010) Pituitary insufficiency after infectious meningitis: a prospective study. J Clin Endocrinol Metab 95(7):3277-3281. https://doi.org/10.1210/ jc.2010-0144

39. Gao L, Guo X, Tian R et al (2017) Pituitary abscess: clinical manifestations, diagnosis and treatment of 66 cases from a large pituitary center over 23 years. Pituitary 20(2):189-194. https:// doi.org/10.1007/s11102-016-0757-7

40. Isidori AM, Arnaldi G, Boscaro M et al (2020) COVID-19 infection and glucocorticoids: update from the Italian Society of Endocrinology Expert Opinion on steroid replacement in adrenal insufficiency. J Endocrinol Invest. https://doi.org/10.1007/s4061 8-020-01266-w

41. Dvorak Z, Pavek P (2010) Regulation of drug-metabolizing cytochrome P450 enzymes by glucocorticoids. Drug Metab Rev 42(4):621-635. https://doi.org/10.3109/03602532.2010.484462

42. Matoulková P, Pávek P, Malý J, Vlček J (2014) Cytochrome P450 enzyme regulation by glucocorticoids and consequences in terms of drug interaction. Expert Opin Drug Metab Toxicol 10(3):425435. https://doi.org/10.1517/17425255.2014.878703

43. Gasmi A, Noor S, Tippairote T, Dadar M, Menzel A, Bjørklund $\mathrm{G}$ (2020) Individual risk management strategy and potential therapeutic options for the COVID-19 pandemic. Clin Immunol 2:108409

44. Elliot ER, Theodoraki A, Jain LR et al (2016) Iatrogenic Cushing's syndrome due to drug interaction between glucocorticoids and the ritonavir or cobicistat containing HIV therapies. Clin Med (Northfield Il) 16(5):412-418. https://doi.org/10.7861/clinmedici ne. $16-5-412$

45. Saberi P, Phengrasamy T, Nguyen DP (2013) Inhaled corticosteroid use in HIV-positive individuals taking protease inhibitors: a review of pharmacokinetics, case reports and clinical management. HIV Med 14(9):519-529. https://doi.org/10.1111/hiv.12039

46. Epperla N, McKiernan F (2015) Iatrogenic Cushing syndrome and adrenal insufficiency during concomitant therapy with ritonavir and fluticasone. Springerplus 4(1):455. https://doi.org/10.1186/ s40064-015-1218-x

47. Woods CP, Argese N, Chapman M et al (2015) Adrenal suppression in patients taking inhaled glucocorticoids is highly prevalent and management can be guided by morning cortisol. Eur J Endocrinol 173(5):633-642. https://doi.org/10.1530/EJE-15-0608

48. Clevenbergh P, Corcostegui M, Gérard D et al (2002) Iatrogenic Cushing's Syndrome in an HIV-Infected patient treated with Inhaled corticosteroids (fluticasone propionate) and low dose ritonavir enhanced PI containing regimen. J Infect 44(3):194-195. https://doi.org/10.1053/jinf.2001.0928

49. Foisy MM, Yakiwchuk EMK, Chiu I, Singh AE (2008) Adrenal suppression and Cushing's syndrome secondary to an interaction between ritonavir and fluticasone: a review of the literature. HIV Med 9(6):389-396. https://doi.org/10.111 $1 / \mathrm{j} .1468-1293.2008 .00579 . x$

50. Samaras K, Pett S, Gowers A, McMurchie M, Cooper DA (2005) Iatrogenic cushing's syndrome with osteoporosis and secondary adrenal failure in human immunodeficiency virusinfected patients receiving inhaled corticosteroids and Ritonavir-Boosted protease inhibitors: six cases. J Clin Endocrinol Metab 90(7):4394-4398. https://doi.org/10.1210/jc.2005-0036

51. Germain RM, Yigit S, Wells L, Giratto JE, Salazar JC (2007) Cushing syndrome and severe adrenal suppression caused by fluticasone and protease inhibitor combination in an HIVinfected adolescent. AIDS Patient Care STDS. 21(6):373-377. https://doi.org/10.1089/apc.2006.0117

52. Zubillaga I, Francés C, Nicolau J, Homar F, Masmiquel L (2017) Adrenal insufficiency and exogenous Cushing's syndrome in a patient receiving inhaled fluticasone and ritonavir. Endocrinol Diabetes y Nutr 64(6):338-339. https://doi.org/10.1016/j.endin u.2017.02.006

53. Molimard M, Girodet P-O, Pollet C et al (2008) Inhaled Corticosteroids and Adrenal Insufficiency. Drug Saf 31(9):769-774. https://doi.org/10.2165/00002018-200831090-00005

54. van den Berg SAA, van Veer NE, Emmen JMA, van Beek RHT (2020) Fluticasone furoate induced iatrogenic Cushing syndrome in a pediatric patient receiving anti-retroviral therapy. Endocrinol Diabetes Metab Case Reports 20:5-8. https://doi. org/10.1530/edm-16-0158

55. Kedem E, Shahar E, Hassoun G, Pollack S (2010) Iatrogenic Cushing's syndrome due to coadministration of Ritonavir and Inhaled Budesonide in an Asthmatic human immunodeficiency virus infected patient. J Asthma 47(7):830-831. https://doi. org/10.3109/02770903.2010.485666

56. Wood BR, Lacy JM, Johnston C, Weigle DS, Dhanireddy S (2015) Adrenal insufficiency as a result of ritonavir and exogenous steroid exposure : report of 6 cases and recommendation for management. J Int Assoc Provid AIDS Care 14(4):300-305. https://doi.org/10.1177/2325957414567681

57. Colpitts L, Murray TB, Tahhan SG, Boggs JP (2017) Iatrogenic Cushing Syndrome in a 47-Year-Old HIV-positive woman on ritonavir and inhaled Budesonide. J Int Assoc Provid AIDS Care 16(6):531-534. https://doi.org/10.1177/2325957417736612

58. Hall JJ, Hughes CA, Foisy MM, Houston S, Shafran S (2013) Iatrogenic Cushing syndrome after intra-articular triamcinolone in a patient receiving ritonavir-boosted darunavir. Int J STD AIDS 24(9):748-752. https://doi.org/10.1177/0956462413 480723

59. Molloy A, Matheson NJ, Meyer PA, Chaterjee K, Gkrania-Klotsas E (2011) Cushing's syndrome and adrenal axis suppression in a patient treated with ritonavir and corticosteroid eye drops. AIDS 25(10):1337-1339. https://doi.org/10.1097/QAD.0b013e3283 $47 \mathrm{c} 09 \mathrm{c}$

60. Dort K, Padia S, Wispelwey B, Moore CC (2009) Adrenal suppression due to an interaction between ritonavir and injected triamcinolone: a case report. AIDS Res Ther 6:4-7. https://doi. org/10.1186/1742-6405-6-10

61. McConkey HZR, Williams H, Kulasegaram R, Graham E (2013) Orbital floor triamcinolone causing Cushing's syndrome in a patient treated with Kaletra for HIV 1. BMJ Case Rep. 3:20122014. https://doi.org/10.1136/bcr.02.2012.5849

62. Schwarze-Zander C, Klingmüller D, Klümper J, Strassburg CP, Rockstroh JK (2013) Triamcinolone and ritonavir leading to druginduced Cushing syndrome and adrenal suppression: description of a new case and review of the literature. Infection 41(6):11831187. https://doi.org/10.1007/s15010-013-0506-z

63. Song Y, Schroeder JR, Bush LM (2014) Iatrogenic cushing syndrome and secondary adrenal insufficiency related to concomitant triamcinolone and ritonavir administration: a case report and review. J Int Assoc Provid AIDS Care 13(6):511-514. https://doi. org/10.1177/2325957413488187

64. Albert NE, Kazi S, Santoro J, Dougherty R (2012) Ritonavir and epidural triamcinolone as a cause of iatrogenic cushing's 
syndrome. Am J Med Sci 344(1):72-74. https://doi.org/10.1097/ MAJ.0b013e31824ceb2b

65. John G, Patrick M, Ollo D (2013) Clinical course and management of iatrogenic Cushing's syndrome after co-administration of injected-triamcinolone and Ritonavir: a systematic review. J Antivir Antiretrovir 05:7. https://doi.org/10.4172/jaa.1000086

66. Peyro-Saint-Paul L, Besnier P, Demessine L et al (2019) Cushing's syndrome due to interaction between ritonavir or cobicistat and corticosteroids: a case-control study in the French Pharmacovigilance Database. J Antimicrob Chemother 74(11):32913294. https://doi.org/10.1093/jac/dkz324

67. Busse KH, Formentini E, Alfaro RM, Kovacs JA, Penzak SR (2008) Influence of antiretroviral drugs on the pharmacokinetics of prednisolone in HIV-infected individuals. J Acquir Immune Defic Syndr 48(5):561-566. https://doi.org/10.1097/QAI.0b013 e31817bebeb

68. Penzak SR, Formentini E, Alfaro RM, Long M, Natarajan V, Kovacs J (2005) Prednisolone pharmacokinetics in the presence and absence of ritonavir after oral prednisone administration to healthy volunteers. JAIDS J Acquir Immune Defic Syndr 40(5):573-580. https://doi.org/10.1097/01.qai.0000187444.38461 .70

69. Oshikoya KA, Oreagba IA, Lawal S et al (2014) Potential drugdrug interactions in HIV-infected children on antiretroviral therapy in Lagos. Nigeria HIV/AIDS Res Palliat Care 6:49-59. https ://doi.org/10.2147/HIV.S52266

70. Sharma M, Saravolatz LD (2013) Rilpivirine: a new non-nucleoside reverse transcriptase inhibitor. J Antimicrob Chemother 68(2):250-256. https://doi.org/10.1093/jac/dks404

71. Cattaneo D, Cheli S, Fusi M, Clementi E, Gervasoni C (2019) Different effects of glucocorticoids on darunavir plasma concentrations. Eur J Clin Pharmacol 75(5):733-735. https://doi. org/10.1007/s00228-019-02626-Z

72. Jallouli M, Galicier L, Zahr N et al (2015) Determinants of hydroxychloroquine blood concentration variations in systemic lupus erythematosus. Arthritis Rheumatol 67(8):2176-2184. https ://doi.org/10.1002/art.39194

73. Flaman AS, Gravel C, Hashem AM, Tocchi M, Li X (2011) The effect of interferon- $\alpha$ on the expression of cytochrome P450 3A4 in human hepatoma cells. Toxicol Appl Pharmacol 253(2):130 136. https://doi.org/10.1016/j.taap.2011.03.019

74. Tapner M, Liddle C, Goodwin B, George J, Farrell GC (1996) Interferon gamma down-regulates cytochrome P450 3A genes in primary cultures of well-differentiated rat hepatocytes. Hepatology 24(2):367-373. https://doi.org/10.1053/jhep.1996.v24.pm000 8690406

75. Raison CL, Borisov AS, Woolwine BJ, Massung B, Vogt G, Miller AH (2010) Interferon- $\alpha$ effects on diurnal hypothalamicpituitary-adrenal axis activity: relationship with proinflammatory cytokines and behavior. Mol Psychiatry 15(5):535-547. https:// doi.org/10.1038/mp.2008.58

76. Carelli M, Porras MC, Rizzardini M, Cantoni L (1996) Modulation of constitutive and inducible hepatic cytochrome(s) P-450 by interferon $\beta$ in mice. J Hepatol 24(2):230-237. https://doi. org/10.1016/S0168-8278(96)80034-1

77. Goebel M, Baase J, Pithan V et al (2002) Acute interferon $\beta-1 b$ administration alters hypothalamic-pituitary-adrenal axis activity, plasma cytokines and leukocyte distribution in healthy subjects. Psychoneuroendocrinology 27(8):881-892. https://doi. org/10.1016/S0306-4530(01)00099-3

78. Then Bergh F, Kümpfel T, Yassouridis A, Lechner C, Holsboer F, Trenkwalder C (2007) Acute and chronic neuroendocrine effects of interferon-beta 1a in multiple sclerosis. Clin Endocrinol (Oxf) 66(2):295-303. https://doi.org/10.1111/j.1365-2265.2006.02725 .x

79. Isidori AM, Jannini EA, Lenzi A, Ghigo E (2020) The Italian Endo-COVID-19. Our response to the emergency. J Endocrinol Invest. https://doi.org/10.1007/s40618-020-01279-5

80. Terpos E, Ntanasis-Stathopoulos I, Elalamy I et al (2020) Hematological findings and complications of COVID -19. Am J Hematol 1:ajh25829. https://doi.org/10.1002/ajh.25829

Publisher's Note Springer Nature remains neutral with regard to jurisdictional claims in published maps and institutional affiliations. 